\title{
CREATING CIVIC-MINDED GRADUATES THROUGH COMMUNITY ENGAGEMENT
}

\author{
Laura Landry-Meyer, Deborah G. Wooldridge, Susan Peet, \& Su Yun Bae \\ School of Family and Consumer Sciences, Bowling Green State University (USA)
}

\begin{abstract}
The purpose is to present community engagement projects embedded in courses guided by Civic-Minded Graduate (CMG) model. The CMG model guides community projects that engage students. A civic-minded graduate $(\mathrm{CMG})$ has completed a course of study and has the capacity and desire to work with others to achieve the common good (Bringle \& Steinberg, 2010). Using the CMG dimensions of identity, educational experiences, and civic experiences (Steinberg, Hatcher, \& Bringle, 2011; Steinberg \& Norris, 2011), examples of community engagement projects will highlight each dimension. Identity dimension example will include an active listening course with campus community as a partner. Educational experience dimension will include student-created informal education programming at a zoo and student interviews with older adult residents. Civic experience dimension will include a student-designed program evaluation for an adoption agency and student support of a music and memory program for older adults with dementia. Impact of students' work on the community and student's sense of civic mindedness will be reported. Implications for using a CMG model for community engagement projects to enhance student learning and strengthen community will be shared.
\end{abstract}

Keywords: Civic-minded graduates, community engagement, active teaching pedagogies.

\section{Introduction}

Civic-mindedness is having a knowledge and involvement in the community with a sense of responsibility and commitment as a member of that community (Bringle, Studer, Wilson, Clayton, \& Steinberg, 2011). The conceptual framework for a civic-minded graduate represents the integration of identity, educational experiences, and civic experiences (Steinberg, Hatcher, \& Bringle, 2011; Steinberg \& Norris, 2011). See Figure 1 for the CMG model (see Figure 1). A student's inclination toward community rather than self is key in this model and nurtured through community-based engagement.

While course-learning outcomes are salient, the outcome of being civic-minded has become important. A student's sense of community and feeling of responsibility toward creates a sense of belonging. Course embedded community engagement experiences create a culture of relationships that nurture students' while simultaneously allowing students to feel a sense of group identity allowing them to work on the developmental task of individual identity.

Figure 1. Civic-Minded Graduate Conceptual Model.

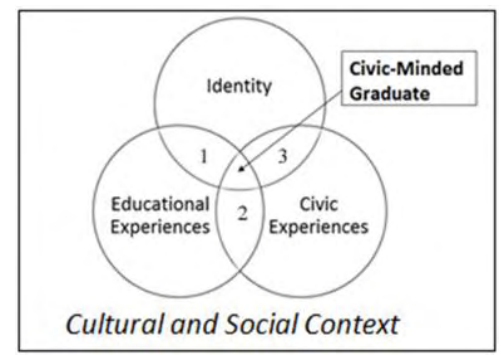




\section{Identity dimension}

The identity dimension integrates a student's self-understanding and awareness with self-concept (Steinberg et al., 2011). Late adolescents, ages 18 to 24, have a developmental need for identity based on psychosocial theory. Providing late adolescents or traditional age college students with opportunities to practice and reflect on the process of "becoming" is developmentally appropriate (Landry-Meyer \& Roe, 2013). Curriculum-based community engagement experiences nurture students' while allowing them to work on the developmental task of identity.

An example of community engagement supporting the identity dimension is an active listening course. The active listening course focuses on listening to self before one is able to listen to others. After mastery of self-awareness about identity primarily through reflection, there is the application of listening skills. Students listen on campus as a required community engagement service to the campus community. Listening on campus requires students to apply active listening skills for the good of the greater campus community.

Engagement with the campus community enhances the learning of active listening skills and increases awareness about the diversity of campus community members. Student listeners listen to others' journeys and challenges. The result is deeper course-based learning about self-awareness combined with campus community involvement and a feeling of commitment to being an active member of the campus community.

\section{Education experience dimension}

The educational experiences dimension represents academic knowledge and technical skills (Steinberg et al., 2011). For college students, learning is the primary reason for attending college. As students increase knowledge and skills, there is a need for higher order cognitive processes to continue to enhance the learning process. Application, analysis, evaluation, and creation are higher order cognitive skills enhanced with community engagement. Subsequently, the impact of students' work on the community can increase a student's sense of civic mindedness.

One example is informal education programming for an area zoo. Students create programs based on academic knowledge and programming and evaluation skills. Rather than a fictional sponsor, students create informal education programs for a community partner, the zoo. The zoo provides passes for students to visit the zoo. Students present final programs to the instructor, classmates, and zoo educational staff. Having the zoo as a community partner enhances student learning and provides insight into the mission and strategic plan of partially public-funded zoo. Students engage with the zoo and extend their programming for the 'public good'.

Another example is student-determined exams that resulted in the interviewing of older adults. Students determined the format of their exams for an upper-level family gerontology course. The student decision was to interview older adults in small teams about concepts learned to determine 'how these concepts were applied in real life'. For the midterm, students worked in small groups to visit an older adult in the community to interview and report their results for the midterm exam. For the final, students invited older adults to class to interview and write application for the final exam. These educational experiences enhanced academic knowledge ( $73 \%$ felt that they learned more through this format) and interviewing skills engaging older adults. The result were relevant assessment of learning and awareness of older adults' experiences in community.

\section{Civic experience dimension}

The civic experiences dimension embodies leadership, participation, civic organization, and service (Steinberg et al., 2011). A student's inclination toward community rather than self is primary focus. Ideally, a student's sense of civic mindedness would be sustainable over time. For college students, the level of community involvement is about depth and breadth. Depth is involvement that evolves into a routine or ongoing commitment to others. Breadth is about various community engagement activities that may include direct or indirect service, advocacy, fundraising, and other contributions. Civic mindedness evolves when students recruit or involve students not enrolled in the same course with community engagement and work toward addressing a community-civic challenge.

Engaging with a nursing home facility to raise awareness and funds for a music and memory program is an example of the civic experience dimension focusing on depth and breadth. Specifically, students in an adult development coursed involved themselves with a music and memory program. This program utilizes music with adults who have dementia to increase quality of life and interpersonal communication. Students became regularly involved with different departments at the nursing home and 
involved friends, family, and the campus community to increase awareness and funds for music supplies (e.g., ipods, headphones). A student-led band marched through the nursing home delivering live music, students celebrated donations with cake and visits, and older adult residents listened to music on personal devices. Students witnessed community engagement that was beyond individualism.

A short-term example that focused more on understanding civic issues within societal context was with a national-based adoption agency. The agency was seeking assistance with evaluating the effectiveness of their awareness campaign about the number of children in foster care seeking permanent families. Becoming familiar with the agency and recognizing the agency's interrelationship with other public and private agencies and funding streams was required of students. Adoption is a civic issue that engaged students in a research methods course. Students operationalized components of the awareness campaign and translated the operationalization into a program logic model. The impact was increased student learning and extension of funding for the adoption agency. Students learned that civic involvement crosses state and regional boundaries. A contextual systems approach enhanced civic identity.

\section{Summary}

Combining course-based assignments with community engagement creates civic-minded graduates. Students transition to a sense of community rather than a sole focus on individual course performance. A CMG model can influence course requirements through assignments and activities. The capacity and opportunity to work with others to achieve the common good is part of the CMG model. The illustration of a CMG model used various course examples in this presentation. These examples illustrate how involvement in a community can integrate the CMG dimensions of identity, education, and civic experiences and enhance student learning.

\section{References}

Bringle, R. G. \& Steinberg, K.S. (2010). Educating for informed community involvement. American Journal of Community Psychology, 46,428-41.

Bringle, R.G., Studer, M., Wilson, J., Clayton, P.H., Steinberg, K.S. (2011). Designing programs with a purpose: To promote civic engagement for life. Journal of Academic Ethics, 9, 149-164.

Landry-Meyer, L. \& Roe, J. (2013). Linking teaching methods and assessment to the developmental needs of family science students, Family Science Review, 18, 1, 117-133.

Steinberg, K.S., Hatcher, J.A., \& Bringle, R.G. (2011). Civic-minded graduate: A north star. Michigan Journal of Community Service Learning, Fall, 19-33.

Steinberg, K.S. \& Norris, K.E. (2011). Assessing civic mindedness. Diversity \& Democracy: Civic Learning for Shared Futures, 14, 12-14. 